\title{
Key Performance Indicators in Libyan Oil and Gas Projects
}

\author{
Mahmoud Matoug ${ }^{1 *}$, Abdulbaset Frefer $^{2}$, Haleema Omer $^{3}$ \\ ${ }^{1,2}$ Mechanical and Industrial Engineering Department, University of Tripoli \\ ${ }^{3}$ Engineering Management Department, University of Tripoli
}

DOI: https://doi.org/10.21467/proceedings.4.48

* Corresponding author email: mmmatoug54@ymail.com

\begin{abstract}
Nowadays, the management system based on key performance indicators (KPIs) is one of the most effective systems from a project management perspective. Unfortunately, common key performance indicators do not exist for the assessment of the performance and success of Libyan oil and gas projects (LOGPs). A project's success or failure no longer depends solely on whether or not it meets traditional key performance indicators (cost, time and quality), instead, the assessment of a project's success is required from the beginning until the end of the project and product lifecycle. The purpose of this study is to advance understanding of KPIs and to develop the most common key performance indicators (KPIs) for the Libyan oil and gas projects. By reviewing the existing research and literature, 11 (eleven) most important KPIs were identified. Questionnaire surveys and semi-structured interviews were administered to gauge the opinions of project practitioners representing clients, consultants and contractors on the KPIs most relevant to the local oil and gas industry. The findings indicate that the traditional KPIs are no longer applicable in measuring performance and success of oil and gas projects in Libya. Other key performance indicators such as Health, Safety and Environment (HSE), Efficiency of use resource, Profitability, Experience gain from the project, Shareholder Satisfaction, Sustainability, Maintainability and Reliability are increasingly becoming more important. Key performance indicators for the assessment of Libyan oil and gas projects are far more complex than simply meeting cost, time and quality.
\end{abstract}

Keywords: Key Performance Indicators (KPIs), Libyan Oil and Gas Projects (LOGPs), Project Management, Project Success, Management Tools.

\section{Introduction}

Oil and gas projects with high level of uncertainty and risks have proven to be one of the most complex in business with high level challenges that are faced by the petroleum companies these days. These projects are executed at different stages of the oil and gas industry value chain and almost always involve multiple stakeholders, multiple nationalities and large number of staff [1]. The size and complexity of these projects require special attention in the project management process. Bodicha [2] argue that despite the globalization and much acquired knowledge for organizations to engage in project management, the use of project management

(C) 2018 Copyright held by the author(s). Published by AIJR Publisher in Proceedings of First Conference for Engineering

Sciences and Technology (CEST-2018), September 25-27, 2018, vol. 2.
This is an open access article under Creative Commons Attribution-NonCommercial 4.0 International (CC BY-NC 4.0)

A iR license, which permits any non-commercial use, distribution, adaptation, and reproduction in any medium, as long as the original work is properly cited. ISBN: 978-81-936820-6-7 
tools and techniques does not automatically guarantee project success. A project performance and success can be measured traditionally by three indicators: namely; cost, time and quality. Many researchers suggest that success can't be accessed only through these three key performance indicators, since project success is more complex. They advocate the expansion of success measurement towards project management success and product success [3]. Libya exports about $80 \%$ of its crude oil and earns about $96 \%$ of its revenue from oil and gas exports [4]. Unfortunately, common KPIs do not exist for the assessment of the performance and success of Libyan oil and gas projects. The purpose of this research paper is to advance understanding of KPIs and to develop a set of the most common KPIs for Libyan oil and gas projects.

\section{Performance Measurement}

Performance measurement is the first step in any performance improvement program. It helps to identify gaps in performance, opportunities for improving performance and to develop programs for continuous improvement. According to Fleming, et al. [5], the heart of effective project management is the establishment of performance measurement baseline and performance reporting. Salaheldin [6] stated that performance measurement is a critical factor for effective management since without measuring something; it is difficult to improve it.

Ofori-Kuragu [7] reported that there isn't distinction between measures and indicators. In fact, measurement alone is not enough to improve performance. The indicators are important within projects since they assess what should be measured and the control limits within which the performance should be. Also, the level of performance that project reaches is based on the efficiency and effectiveness of the actions taken. According to Alarcon, et al. [8], the result of a project is the product of various processes and decisions that interact during its execution. Along the same line, Libyan oil and gas industry represented by the National Oil Corporation (NOC) and its subsidiaries, most of which are focusing on traditional key performance indicators (cost, time and quality). Although KPIs have long been used to evaluate and judge the performance and success of projects; many researchers suggest that success can't be accessed only through those traditional KPIs, since project success is more complex, and these indicators do not provide an adequate vision of the potential for improvement [9]. In a recent study conducted to determine the strength of the relationship between different elements of project management performance indicators and project success, the results showed that the project management performance indicators have positive association with the project success [10]. Many studies that were carried out to determine KPIs to evaluate the performance and success of projects did not distinguish between "indicators and criteria", describing both as measures used to measure the performance and success [1]. In this research paper, "indicators" and "criteria" are both used as means to measure the performance and success, and hence used interchangeably. 
Key Performance Indicators in Libyan Oil and Gas Projects

In order to cover key performance indicators in greater depth, it is important to consider the various studies conducted on the construction industry. Although the oil and gas projects have unique characteristics, they have similarities with construction projects. Some of the construction projects in the oil and gas industry include the construction of oil refineries, of petrochemical plants or of gas treatment plants. Table 1 shows summary of key performance indicators in any project from the fifteen literature reviews discussed in this research paper [3,7,11-23]. The broad categories of stakeholders have been identified by many researchers, such as clients, contractors, consultants and material suppliers as the internal project stakeholders; where, the external stakeholders were identified as local communities and the government. Stakeholder participation in project evaluation is essential since it keeps the projects on track and often ensures early detection of problems that can reduce the likelihood of having major cost overruns or time delays and non-conformity to project specification [14]. Many researchers identified clients, contractors and consultants as the major internal stakeholders in projects, and their participation is essential in the evaluation of any project. The clients are considered as the financiers interested in how much had been spent and its corresponding progress. Whereas the contractors and the professional consultants were integral to the project implementation and the success or failure of the project depends on their performance [15]. In this research paper the authors consider stakeholders as clients, contractors and consultants.

Table 1: Summary of KPIs in Project from the Literature Review.

\begin{tabular}{|c|c|c|c|c|c|c|c|c|c|c|c|c|c|c|c|c|}
\hline Sotrces & 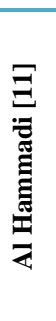 & 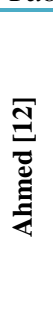 & 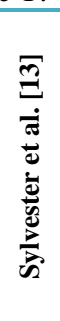 & 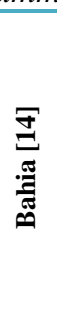 & 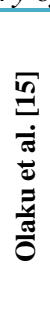 & 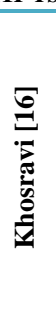 & 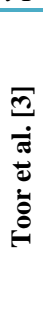 & 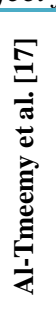 & 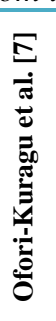 & 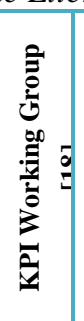 & 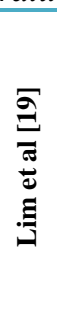 & 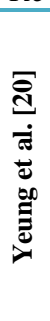 & 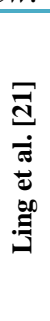 & 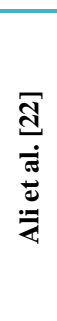 & 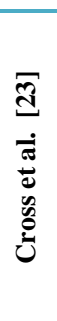 & 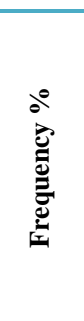 \\
\hline Cost & $\sqrt{ }$ & $\sqrt{ }$ & $\sqrt{ }$ & $\sqrt{ }$ & $\sqrt{ }$ & $\sqrt{ }$ & $\sqrt{ }$ & $\sqrt{ }$ & $\sqrt{ }$ & $\sqrt{ }$ & $\sqrt{ }$ & $\sqrt{ }$ & $\sqrt{ }$ & & $\sqrt{ }$ & $93.3 \%$ \\
\hline Time & $\sqrt{ }$ & $\sqrt{ }$ & $\sqrt{ }$ & $\sqrt{ }$ & $\sqrt{ }$ & $\sqrt{ }$ & $\checkmark$ & $\sqrt{ }$ & $\sqrt{ }$ & $\sqrt{ }$ & $\sqrt{ }$ & $\sqrt{ }$ & $\sqrt{ }$ & & $\sqrt{ }$ & $93.3 \%$ \\
\hline Quality & $\sqrt{ }$ & & $\sqrt{ }$ & $\sqrt{ }$ & $\sqrt{ }$ & $\sqrt{ }$ & $\sqrt{ }$ & $\sqrt{ }$ & $\sqrt{ }$ & $\sqrt{ }$ & $\sqrt{ }$ & $\sqrt{ }$ & $\sqrt{ }$ & $\sqrt{ }$ & $\sqrt{ }$ & $93.3 \%$ \\
\hline $\begin{array}{r}\text { Customer } \\
\text { Satisfaction }\end{array}$ & $\sqrt{ }$ & & & $\sqrt{ }$ & $\sqrt{ }$ & $\sqrt{ }$ & & $\sqrt{ }$ & $\sqrt{ }$ & $\checkmark$ & & & v & $\sqrt{ }$ & $\sqrt{ }$ & $66.7 \%$ \\
\hline $\begin{array}{l}\text { Health, } \\
\text { Safety and } \\
\text { Environment }\end{array}$ & $\sqrt{ }$ & & & $\sqrt{ }$ & & $\sqrt{ }$ & $\sqrt{ }$ & & $\sqrt{ }$ & $\sqrt{ }$ & $\sqrt{ }$ & & & $\sqrt{ }$ & & $53.3 \%$ \\
\hline Scope & & $\sqrt{ }$ & $\sqrt{ }$ & $\sqrt{ }$ & & & & & & & & & & & & $20 \%$ \\
\hline $\begin{array}{l}\text { Efficiency of } \\
\text { use resources }\end{array}$ & & & & & $\checkmark$ & & $\sqrt{ }$ & & & & & & $\sqrt{ }$ & & & $20 \%$ \\
\hline Effectiveness & & & & & $\sqrt{ }$ & & $\sqrt{ }$ & & & & & & $\sqrt{ }$ & & & $20 \%$ \\
\hline Productivity & & & & & & & & & $\sqrt{ }$ & & & & & & $\sqrt{ }$ & $13.3 \%$ \\
\hline $\begin{array}{r}\text { Business } \\
\text { performance }\end{array}$ & & & & & & & & & $\sqrt{ }$ & $\checkmark$ & & & & & & $13.3 \%$ \\
\hline Profitability & & & & & & & & & & & & & $\sqrt{ }$ & $\sqrt{ }$ & & $13.3 \%$ \\
\hline
\end{tabular}

ISBN: 978-81-936820-6-7 


\section{Data Collection}

This research paper was conducted based on intensive literature reviews to identify key performance indicators for oil and gas projects and to develop a survey questionnaire. Based on these literature reviews eleven (11) key performance indicators were identified in Libyan oil and gas sector. Table 1 presents the proposed key performance indicators of oil and gas projects success. The questionnaire consists of two sections. The first elicits information on the respondents' background as shown in Table 2, where the second consists of questions related to key performance indicators. The questionnaire survey was carried out in Libya in the beginning of 2017. Internal consistency of the data reliability analysis was achieved by employing Cronbach's Alpha coefficient. Cronbach's Alpha reliability coefficient ranges from 0 to1. The closer the coefficient value to 1 , the greater is the internal consistency of the data $[13,24,25]$. Cronbach's Alpha coefficient for each field of the questionnaire is 0.843 , this is considered high; the result is ensuring the reliability of each field of the questionnaire.

One hundred and twenty (120) questionnaires were administered to project practitioners, including clients, consultants and contractors who have experience in oil and gas projects that were recommended by the NOC, as part of the most important companies which have great experience in oil and gas projects in Libya. Out of the 120 distributed by hand, eighty-eight (88) were received back. Therefore, the questionnaires returned have a response rate of $73.33 \%$. The respondents were requested to indicate their views on the importance of each key performance indicator. They were asked to use five-point Likert Scale ranging from 1 to 5 , where 1 represents strongly disagree and 5 strongly agree. This scale was introduced by Likert in 1932 [26-27].

Table 2: Summary of Respondents' Profile.

\begin{tabular}{|c|c|}
\hline Companies & $\%$ \\
\hline Client & 48.86 \\
\hline Consultant & 23.86 \\
\hline Contractor & 27.27 \\
\hline & \\
\hline & \\
\hline
\end{tabular}

\begin{tabular}{|c|c|}
\hline Qualification & $\%$ \\
\hline HND & 4.55 \\
\hline BSC & 53.41 \\
\hline MSC & 39.77 \\
\hline PHD & 2.27 \\
\hline Other & 0 \\
\hline
\end{tabular}

\begin{tabular}{|c|c|}
\hline Experience (years) & $\%$ \\
\hline $1-5$ & 13.95 \\
\hline $6-10$ & 29.07 \\
\hline $11-15$ & 16.28 \\
\hline $16-20$ & 13.95 \\
\hline Above 20 & 26.74 \\
\hline
\end{tabular}

\section{Results and Discussion}

\subsection{Data Analysis}

The data collected were analyzed with the aid of Statistical Package for Social Sciences (SPSS). Descriptive statistics were used to analyze the respondents' profiles using SPSS. The Relative Importance Index (RII) method [22,28-30] was used to rank the key performance indicators.

Proceedings of First Conference for Engineering Sciences and Technology (CEST-2018), vol. 2 
Key Performance Indicators in Libyan Oil and Gas Projects

This method provides a score calculated upon the weight given to $i^{\text {th }}$ response (Wi), $(i=1,2,3,4,5)$; frequency of the $i^{\text {th }}$ response $(\mathrm{Xi})$; maximal weight $(\mathrm{A})$ (5 in this research paper); and total number of respondents $(\mathrm{N})$. RII refers to a value within [0-1] interval. The higher the RII, the more important the KPI. The RII for each KPI is calculated using the formula below [22]:

$$
R I I=\frac{\sum_{i=1}^{5} W i X i}{A * N}
$$

\subsection{RII and KPIs Used to Assess Performance and Success of LOGPs}

From the perspective of the clients, consultants and contractors, all the eleven key performance indicators identified in the literature review were significant in the Libyan oil and gas industry, since all had RII score values above 0.7 . The different categories of respondents seem to have a few different views about the most important KPIs. Table 3 shows the full details of RII scores of all key performance indicators.

Table 3: Shows the full details of RII scores of all key performance indicators.

\begin{tabular}{|c|c|c|c|c|c|c|c|c|}
\hline $\begin{array}{l}\text { Key Performance } \\
\text { Indicators }\end{array}$ & $\begin{array}{c}\text { RII } \\
\text { (Client) }\end{array}$ & Rank & $\begin{array}{c}\text { RII } \\
\text { (Consultant) }\end{array}$ & Rank & $\begin{array}{c}\text { RII } \\
\text { (Contractor) }\end{array}$ & Rank & $\begin{array}{c}\text { Overall } \\
\text { RII }\end{array}$ & $\begin{array}{l}\text { Overall } \\
\text { Rank }\end{array}$ \\
\hline Quality & 0.9395 & 2 & 0.9333 & 1 & 0.9333 & 1 & 0.9364 & 1 \\
\hline Time & 0.9442 & 1 & 0.9238 & 2 & 0.9250 & 2 & 0.9341 & 2 \\
\hline Cost & 0.9395 & 2 & 0.8952 & 3 & 0.9167 & 3 & 0.9227 & 3 \\
\hline $\begin{array}{l}\text { Health, Safety and } \\
\text { Environment }\end{array}$ & 0.9023 & 3 & 0.8571 & 5 & 0.8500 & 7 & 0.8773 & 4 \\
\hline Scope & 0.8791 & 4 & 0.8476 & 6 & 0.8500 & 7 & 0.8636 & 5 \\
\hline Customer satisfaction & 0.8279 & 5 & 0.8857 & 4 & 0.8833 & 5 & 0.8568 & 6 \\
\hline $\begin{array}{l}\text { Efficiency of use of } \\
\text { resources }\end{array}$ & 0.8093 & 6 & 0.8476 & 6 & 0.9000 & 4 & 0.8432 & 7 \\
\hline Effectiveness & 0.8047 & 7 & 0.8476 & 6 & 0.8417 & 8 & 0.8250 & 8 \\
\hline Productivity & 0.7953 & 8 & 0.8476 & 6 & 0.8250 & 9 & 0.8159 & 9 \\
\hline Profitability & 0.7814 & 9 & 0.8190 & 7 & 0.8667 & 6 & 0.8136 & 10 \\
\hline Business performance & 0.7395 & 10 & 0.7429 & 8 & 0.7667 & 10 & 0.7477 & 11 \\
\hline
\end{tabular}

The overall rankings of the most important key performance indicators are; Quality with an overall RII of 0.9364 , followed by Time with 0.9341 , then Cost with 0.9227 , and finally Health, Safety and Environment (HSE) with 0.8773 . RII scores equal or less than 0.8 were omitted. The results from this research paper indicate that quality has been ranked by the clients as the second most important indicator, while consultants and contractors ranked the quality as first indicator, this is an indication that quality is the most important indicator for consultants and contractors. Time has been ranked by the clients as the first, this is an indication that time is the most important indicator for clients because overrun of time shatters all subsequent planning. However, both consultants and contractors ranked time as the second most important indicator. Cost has been ranked by the clients as the second, while consultants and 
contractors ranked it as the third; indeed, most project managers must ensure that the implemented projects do not experience cost overruns.

In one hand, Health, Safety and Environment (HSE) indicator has been ranked by the clients as the third indicator. Many industries, especially the oil and gas sector need to give priority consideration to the HSE, this necessitates that companies must track the number of dangerous occurrences, occupational injuries and oil spills to avoid damaging their reputation and to maintain the competitive advantage. On the other hand, HSE has been ranked by the consultants as the fifth indicator and by the contractors as the seventh indicator. Scope indicator has been ranked by the clients, consultants and contractors the fourth, sixth, and seventh indicator, respectively. Projects in oil and gas are carried out with specific scope aiming to achieve specific deliverables [13].

While clients and contractors ranked the Customer' Satisfaction indicator as the fifth, consultants ranked it as the fourth. Customer satisfaction is considered as an important KPIs when evaluating a project's performance and the success of a project that meets the end-users' expectations [11]. Efficiency of use of resources has been ranked by both the clients and consultants as the sixth indicator; it was ranked as the fourth indicator by the contractors. Effectiveness has been ranked by the clients as the seventh indicator but it was ranked by consultants and contractors as the sixth and eight indicator, respectively.

Productivity has been ranked by the clients as the eight indicator. The consultants and contractors ranked productivity as the sixth and ninth, respectively. Profitability has been ranked by the clients and consultants as the ninth and seventh indicator, respectively. However, it has been ranked by the contractors as the sixth indicator. The fact that survival of companies in the long-term depends on their ability to be profitable, this indicator is used to assess project success in the mid-term and long-term [25]. Business performance has been ranked by the clients and contractors as the tenth indicator and ranked as the eight indicator by the consultants.

\subsection{Interviews and New Key Performance Indicators}

Following the analysis of the questionnaire survey results, interviews were conducted with experts in the Libyan oil and gas projects from oil and gas industry to validate the results of this research and add any absent key performance indicators in the initial questionnaire survey. Five semi-structured interviews were conducted based on the result of the initial survey.

Interviewees were asked to comment on the outcome of the questionnaire survey and make suggestions for the final list of KPIs for Libyan oil and gas projects. The questions sought to establish whether the interviewees agreed with the outcome of the questionnaire analysis. The interviewees agreed and added more five indicators; namely, Experience Gain from the Project, Shareholder Satisfaction, Achievement of Project's Objectives, Reliability, Maintainability and Sustainability as the KPIs for Libyan oil and gas projects.

Proceedings of First Conference for Engineering Sciences and Technology (CEST-2018), vol. 2 


\section{Conclusions}

One of the most important conclusions that were reached from the literature and confirmed in this research paper is that the key performance indicators in projects in the construction industry seem to have similarities with the key performance indicators in projects in the oil and gas industry. Although many researchers have proposed various key performance indicators to measure both oil and gas project and construction success, there is no general agreement. Other significant conclusions are; the oil and gas industry are slowly departing from the traditional quantitative performance measurement to a rather mix of both quantitative and qualitative performance measurement; the results indicate that the traditional (Iron Triangle) KPIs only, are no longer applicable in measuring the performance and success of oil and gas projects in Libya. This fact should serve as an encouragement in finding a commonly accepted set of KPIs that will be used for performance benchmarking of the oil and gas projects. From the results of this research paper, other key performance indicators, such as Health, Safety and Environment (HSE), Efficiency of use resource, Profitability, Experience Gain from the project, Shareholder Satisfaction, Sustainability, Maintainability and Reliability are increasingly becoming more important. Libyan oil and gas companies need to think in more depth about the key performance indicators that are currently used globally in evaluating their projects and serve towards further setting new indicators to meet short-term, mid-term and long-term objectives in future projects. Sustainability has been identified as one of the most key performance indicators of oil and gas projects in Libya, also through literature review, the sustainability is considered to be one of the future developments in project management. Therefore, the researchers recommend further study to find the relationship between project management and sustainability, and the ability of oil and gas companies to implement sustainability's principles in project management in Libya.

\section{References}

[1] H. Omer, "Assessment of Projects Using Key Performance Indicators in Oil and Gas Companies", MSc Thesis, University of Tripoli, 2017.

[2] H. Bodicha, "How to Measure the Effect of Project Risk Management Process on the Success of Construction Projects: A Critical Literature Review", The International Journal of Business \& Management, vol 3, no. 12, 2015.

[3] S. Toor and O. Ogunlana, "Beyond the 'Iron Triangle': Stakeholder Perception of Key Performance Indicators (KPIs) for Large Scale Public Sector Development Projects”, International Journal of Project Management, pp. 228-236, 2010.

[4] Independent Statistics \& Analysis,” Country Analysis Brief: Libya”, U.S. Energy Information Administration, 2015.

[5] Q. Fleming and J. Koppleman, "Earned Value Project Management", 2nd ed., Project Management Institute, Newton Square, PA: PMI, 2000.

[6] S. Salaheldin, "Critical Success Factors for TQM Implementation and their Impact on Performance of SMEs", International Journal of Productivity and Performance Management, vol. 58, no. 3, pp. 215-237, 2009.

[7] J. Ofori-Kuragu, F. Edum-Fotwe and E.Badu, "Key Performance Indicators for Project Success in Ghanaian Contractors", International Journal of Construction Engineering and Management, vol. 5, no. 1, pp. 1-10, 2016.

[8] L. Alarcon, A. Grillo, J. Freire and S. Diethelm, "Learning from Collaborative Benchmarking in the Construction Industry", 9th Annual Conference of the International Group for Lean Construction (IGLC-9), Singapore, 2001.

[9] A. Inkpen and M. Mofett, "The Global Oil and Gas Industry: Management, Strategy, and Finance", PennWell Corporation, Tulsa, USA, 2011.

[10] H. Maylor, "Project Management", Pearson Education Limited, 4th ed., UK, 2010.

[11] N. Al-Hammadi, "KPIs for Assessing Project Performance in the Oil and Gas Industry of the United Arab Emirates", 6th Engaged Management Scholarship Conference, September 2016, University Paris-Dauphine, Paris, France. 
[12] M. Ahmed, "Critical Factors for the Success of Projects in Oil and Gas Sector of Kuwait", MSc Thesis, Department of Management Sciences, Virtual University of Pakistan, Pakistan, 2011.

[13] D. Sylvester, N. Abdul Rani and J. Shaikh, "Comparison Between Oil and Gas Companies and Contractors Against Cost, Time, Quality and Scope for Project Success in Miri, Sarawak, Malaysia", African Journal of Business Management, vol. 5, no. 11, pp. 4337- 4354, 2001.

[14] F. Bahia, "Analysis of Success Criteria in Engineering, Procurement and Construction (EPC) Projects", Revista Gestao e Projetos - GeP, Sao Paulo, vol. 1, no. 2, pp. 49-67, 2010.

[15] A. Olaku, A. Abdulmumin, S. Ibrahim and T. John, "Evaluation of Perception of Stakeholders on Key Performance Indicators for U.B.E Building Projects, Journal of Multidisciplinary Engineering Science and Technology (JMEST), vol. 2, no. 3, pp. 277- 285, 2015.

[16] S. Khosravi and H. Afshari, "A Success Measurement Model for Construction Projects", International Conference on Financial Management and Economics, vol. 11, pp. 186-190, 2011.

[17] S. Al-Tmeemy, H. Abdul-Rahman and Z. Harun, "Future Criteria for Success of Building Projects in Malaysia", International Journal of Project Management, vol. 29, no. 3, pp. 337-348, 2011.

[18] KPI Working Group, "The KPI Report for the Minister for Construction", Department for Transport and Environment, London, 2000.

[19] C. Lim and M. Mohamed, "Criteria of Project Success: An Exploratory Re-Examination", International Journal of Project Management, vol. 17, no. 4, pp. 243-248, 1999.

[20] F. Yeung, A. Chan and D. Chan, "A Computerized Model for Measuring and Benchmarking the Partnering Performance of Construction Projects", Automation in Construction, vol. 18, no, 8, pp. 1099-1113, 2009.

[21] F. Ling, S. Low, S.Wang and H. Lim, "Key Project Management Practices Affecting Singaporean Firms' Project Performance in China", International Journal of Project Management, 2009.

[22] H. Ali, I. Al-Sulaihi and K. Al-Gahtani, "Indicators for Measuring Performance of Building Construction Companies in Kingdom of Saudi Arabia”, Journal of King Saud University - Engineering Sciences, vol. 5, pp125-134, 2013.

[23] K. Cross and R. Lynch, "The SMART Way to Define and Sustain Success", National Productivity Review, vol. 8, no. 1, pp. 23- 33, 1989.

[24] L. Cronback, "Coefficient Alpha and the Internal Structure of Tests", Psychometrika, vol. 16, no. 3, pp. 297-334, 1951.

[25] Y. Yang and S. Green, "Coefficient Alpha: A Reliability Coefficient for the 21st Century", Journal of Psychoeducational Assessment, vol. 29, pp. 377-392, 2011.

[26] P. Vonglao, “Application of Fuzzy Logic to Improve the Likert Scale to Measure Latent Variables", Kasetsart Journal of Social Sciences, vol. 38, no. 3, pp. 337-344, 2017.

[27] R. Likert, "A Technique for the Measurement of Attitudes", Archives of Psychology, vol 22, no 140, pp. 5-55, 1932.

[28] K. Al-Gahtani, I. Al-Sulaihi, R. Al Rashed and A. Batarfi, "Key Performance Indicators for Value Management in Saudi Construction Industry", International Journal of Application or Innovation in Engineering \& Management (IJAIEM), vol. 4, no. 11, pp. 54-62,2015

[29] M. Nourbakhsh, S. Mydin, R. Zin, S. Zolfagharian, J. Irizarry and M. Zahidi, "Relative Importance of Key Performance Indicators of Construction Projects Towards Buildability at Design Stage", Advanced Materials Research Online: vols. 446-449, pp. 340-344, 2012.

[30] V. Tam, C. Tam and W. Ng, "On Prefabrication Implementation for Different Project Types and Procurement Methods in Hong Kong”, Journal of Engineering, Design and Technology, vol. 5, no. 1, pp. 68-80, 2007. 